\title{
Abdominal Physical Signs and Medical Eponyms: Part II. Percussion and Auscultation, I924- 1980
}

\author{
Vaibhav Rastogi, MD; Devina Singh, MD; Halil Tekiner, PhD; Fan Ye, MD; \\ Joseph J. Mazza, MD; and Steven H. Yale, MD
}

\begin{abstract}
Background: Percussion and auscultation are derived from the Latin words to touch and hear, respectively. Covered are abdominal percussion signs and ausculatory signs discovered from I924 to I980. Signs ascribed as medical eponyms pay homage to these physicians who provided new and unique insights into disease.

Data sources: PubMed, Medline, online Internet word searches, textbooks, and references from other source text. PubMed was searched using the Medical Subject Heading (MeSH) of the name of the eponyms and text words associated with the sign.

Conclusion: Many of these signs have been discarded because of modern imaging and diagnostic techniques. When combined with a high clinical suspicion, positive results using percussion combined with palpation is a useful bedside technique in detecting splenic enlargement. Thus, some of these maneuvers remain important bedside techniques that skilled practitioners should master, and along with a meaningul history, provide relevant information to diagnosis. It is through learning about these signs that we gain a sense of humility on the difficulty physicians faced prior to the advent of techniques that now allow us an easier way to visualize and diagnose the underlying disease processes.
\end{abstract}

Keywords: Percussion; Auscultation; Abdomen; Signs; Eponyms; History of Medicine

$\mathrm{I}$ $\mathrm{n}$ part I, medical eponyms associated with abdominal percussion signs discovered during the mid-late nineteenth century were discussed. In this paper, we cover the historical aspects, original description, performance, and validity of signs for percussion and auscultation in modernday bedside clinical practice for those described beginning in the nineteenth century. These include signs associated with obturator hernias, spleen, and appendix.

Auscultation is derived from the Latin word, auscultare, meaning to listen or to hear with attention. ${ }^{1}$ Auscultation of the abdomen follows inspection with percussion, the last skill performed after palpation. In addition to listening for peristaltic bowel sounds, abdominal auscultation encompasses listening for altered bowel sounds, rubs, hums, murmurs, succession splash, peritoneal friction rub, or vascular bruits and consists of placing the diaphragm of the stethoscope to the abdominal wall over each abdominal quadrant. In the case of inflammatory enlargement, a rub may be heard over the liver, spleen, or abdominal mass. The areas over the aorta and renal arteries should be auscultated for the presence of bruits. Auscultation of the heart and chest dates back to Hippocrates in the fourth century BC, with the term "direct" method coined by Foës. ${ }^{1}$ In his book Treatise of the Diseases of the Chest and on Mediate Auscultation, Laënnec (1829) wrote:

Hippocrates has made trial of immediate auscultation, as is proved by the following passage of the treatise De Morbis: "You shall know by this that the chest contains water and not pus, if in applying the ear during a certain time on the side, you perceive a noise like that of boiling vinegar." I need hardly state that the assertion as far as the
Corresponding Author: Steven H.Yale, MD, University of Central Florida College of Medicine, Department of Internal Medicine, 6850 Lake Nona Blvd, Orlando, FL 32827, Email: steven.yale.md@gmail.co
Received: March 18, 2018

Revised: October 13, 2018

Accepted: October 24, 2018

doi: $10.3121 / \mathrm{cmr} .2018 .1429$ 
diagnosis is concerned, is erroneous. The sound heard by Hippocrates was probably that of simple respiration, or this intermixed with a crepitous rattle. It is very singular that this passage seems never to have engaged the attention of physicians, and there is no evidence that his experiment has ever been repeated until the present time. It is true that I had myself read this passage of Hippocrates many years before I entertained the idea of mediate auscultation but at the time I considered it, as it indeed is, one of the mistakes of that great man, and had altogether forgotten it. ${ }^{2(\text { p. } 24)}$

In the introduction to his book De l'Auscultation Médiate ou Traité du Diagnostic des Maladies des Poumons et du Cour (On Mediate Auscultation or Treatise on the Diagnosis of the Diseases of the Lungs and Heart), Laënnec wrote about the current direct method of auscultation followed by his new indirect method of auscultation approach to the lungs and breath sounds:

The first idea may have been drawn from a passage by Hippocrates which I shall have occasion to examine elsewhere; it is so simple, however, that it must be very ancient; however, I do not know that any one has ever gained a certain share of it; and this is doubtless due to the fact that it can often be misleading, for various reasons which will be explained in its own place. As inconvenient to the physician as to the patient, it is almost impracticable and unpleasant in the hospitals; it is rarely proposed in most women, and in some even the volume of the breasts is a physical obstacle to its use. ${ }^{3(\mathrm{pp} .6-7)}$ (...) In 1816, I was consulted for a young person who presented with general symptoms of heart disease, and in which application of the hand and percussion gave little result on account of the patient being overweight. The age and sex of the patient preventing the kind of examination of which I have just spoken. I came to recollect a well-known phenomenon of acoustics; if one applies the ear to the end of a beam, one hears very distinctly a pin-stroke at the other end. I imagined that, in the case in question, it might be possible to make use of this property of bodies. I took a notebook of paper, I formed a very tight roller of which I applied one end to the precordial region, and, with my ear at the other end, I was as surprised as it was to hear the beating of the heart in a much more distinct manner than I had ever done by the immediate application of the ear. ${ }^{3(\mathrm{pp} .7-8)}$

Some of these signs, although not studied to confirm their validity, may still be useful in conjunction with other key findings detected through a detailed history and physical examination to assist with diagnosis. The signs will be presented based on the year that they were first reported.

\section{Data Sources}

PubMed, Medline, online Internet word searches, and bibliographies from source text and textbooks were used.
PubMed was searched using the Medical Subject Heading (MeSH) of the name of the eponyms and text words associated with the sign.

\section{Razdolsky Sign or Mendel-Razdolsky Sign}

Ivan Yakovlevich Razdolsky (also referred to as Razdolskii or Rasdolsky) (1890-1962) received his medical degree in 1919 from the military-medical academy in St. Petersburg, Soviet Union. ${ }^{4}$ In 1947 he was appointed chair to the Leningrad Sanitary and Hygienic Medical Institute 4 and also served as Associate Editor of Questions of Neurosurgery and Neuropathology and Pscyhiatry of SS Korsakov magazine. In 1946 he was a member of the Medical Academy of Science in USSR..$^{5}$

Razdolsky sign has been described in conjunction with the name Mendel as a sign of appendicitis produced by "percussion of the right anterior abdominal wall superior to the iliac bone with a percussion hammer causes pain in the right iliac area." ${ }^{6-8} \mathrm{We}$ were unable to locate the original article to substantiate this claim. Mendel, however, described a sign of epigastric percussion used in the diagnosis of peptic ulcer disease, and Razdolsky (1924) is credited for describing the crossed spino-adductor reflex, which consists of a (Tables 1 and 2):

[c]ontraction of the adductor muscles of the opposite side when tapped with the hammer at the anterior superior iliac spine. It manifests itself as a tightening and inward contraction of the opposite leg. Much less frequently (20$25 \%$ ) and only in persons with prominent tendon and periosteal reflexes, is the shortening of the crossed adductors accompanied by a gradual contraction of the muscles on the same side as the stimulus. In such cases the crossed reflex is much stronger than the homolateral one. ${ }^{9 \text { (p. 658; emphasis added) }}$

The reflex is performed as follows:

In order to produce the reflex, the observer must be placed on the back with his hips pulled closed and slightly turned outwards. With the percussion hammer you must apply short strokes directly to the anterior superior illiac spine. Transmission to the nearest parts of the illiac crest provokes, instead of this reflex, a contraction of the tensor fasciae latae, and in stronger strokes also of the quadriceps muscle. ${ }^{9(\mathrm{pp} .658-659 \text {; emphasis added) }}$

The spino-adductor reflex is found in $98 \%$ of people. ${ }^{9}$ In unilateral damage to the coricospinal tract it is always increased on the diseased side. In patients with localized damage to the posterior root or peripheral sensory nerve, such as in tabes dorsalis, the adductor reflex is absent on the corresponding and opposite side. If the motor nucleus or peripheral nerve fibers are damaged in patients with myelitis or those recovering from polymyelitis, both the homolateral and crossed spinal adductor reflex will be absent on the 
diseased side, while the crossed spino-adductor reflex is preserved on the opposite side.

F. Mendel (1901) in his paper entitled Die direkte Perkussion des Epigastrium, ein diagnostisches Hilfsmittel bei Ulcus ventriculi (The direct percussion of the epigastrium, a diagnostic tool for gastric ulcer) reported on the limitation of epigastric pressure to detect peptic ulcer disease:

The sensitivity to pressure cannot be concluded with certainty. Patients with gastric ulcers tend to be anemic and nervous. They may not feel any pressure pain in the epigastrium, and tend to lack hypersensitivity, especially when the ulcerative processes take place on the posterior wall of the stomach, or the ulcer is seated under the costal arch, where it is not accessible to palpation. ${ }^{10(\text { p. } 565)}$

He described the method for detecting gastric and duodenal ulcers, and for following the course of disease (Table 1):

If you use the percussion hammer to make light, short strokes on the epigastrium with the abdomen as relaxed as possible, even the most sensitive patient will not feel pain as long as the stomach and neighboring structures are healthy. However, if the patient suffers from gastric ulcer, the percussion carried out will very soon reach a point where even the slightest impact is perceived as an intense pain, which is always followed by a more or less prolonged after-pain. If we percuss the epigastrium in radial direction from the first point of pain found, mark all those points sensitive to pain and connect all these points together, in the vast majority of cases we will define a circular area. Within this sharply delineated zone even the slightest percussion is painful while outside its limit even heavier strokes do not cause pain. (...) If we now mark the boundary of that region from which we can exert a painful stimulus on an existing ulcer by the direct percussion of the epigastrium, we project, as it were, the image of the stomach ulcer on the abdominal wall. Although this picture, according to its position and size, does not need to correspond to that of the ulcer, it is, as further observation of the course of healing teaches dependent on the particular condition of the gastric ulcer: it diminishes with the reduction of the ulcer and disappears with the healing of the same. (...) By means of the direct percussion of the epigastrium, we will still be able to secure the diagnosis even if palpation does not provide a pressuresensitive site which corresponds to the anatomical position

Table 1. Summary of abdominal physical signs of percussion (1924-1980)

\begin{tabular}{|c|c|c|c|c|}
\hline Sign & Year & Description & Sensitivity & Specificity \\
\hline \multirow{4}{*}{$\begin{array}{l}\text { Mendel- } \\
\text { Razdolsky }\end{array}$} & \multirow{4}{*}{$\begin{array}{l}1910 \\
1924\end{array}$} & Mendel & \multirow{4}{*}{ Unknown } & \multirow{4}{*}{ Unknown } \\
\hline & & $\begin{array}{l}\text { With the patient supine and abdomen relaxed apply light, short } \\
\text { strokes to the epigastrium to identify the first point of pain. From } \\
\text { this site continue percussing the abdomen outward in a radial } \\
\text { direction (like the spoke of a wheel) moving from the sensitive to } \\
\text { non-sensitive areas. At these transitions, connect these outer } \\
\text { points. }\end{array}$ & & \\
\hline & & $\underline{\text { Razdolsky }}$ & & \\
\hline & & $\begin{array}{l}\text { Spino-adductor reflex: Patient supine, knees flexed, hips flexed } \\
\text { on abdomen and slightly externally rotated. Using a reflex } \\
\text { hammer apply short strokes on the anterior superior illiac spine. }\end{array}$ & & \\
\hline Kenawy & 1937 & $\begin{array}{l}\text { Ausculatory finding of venous hum below the xiphoid process } \\
\text { increased during inspiration. }\end{array}$ & Unknown & Unknown \\
\hline Nixon & 1954 & $\begin{array}{l}\text { Patient in the right lateral decubitus position with left arm } \\
\text { extended forward and upward so as to not impede access to the } \\
\text { left lower thorax. Palpate the lower border of inspiration and } \\
\text { begin percussion in the region of the posterior axillary line } \\
\text { moving downward obliquely on a perpendicular line toward the } \\
\text { lower midanterior costal margin. }\end{array}$ & $25-66 \%$ & $68-95 \%$ \\
\hline Castell & 1967 & $\begin{array}{l}\text { With the patient supine percuss using the middle finger of the } \\
\text { left hand in the eighth or ninth intercostal space (lowest). } \\
\text { Percussion produces a resonant note occurring with full } \\
\text { inspiration and expiration. }\end{array}$ & $25-85 \%$ & $32-94 \%$ \\
\hline $\begin{array}{l}\text { Hannington- } \\
\text { Kiff }\end{array}$ & 1980 & $\begin{array}{l}\text { With a reflex hammer, apply a firm blow over the thumb or index } \\
\text { finger } 5 \mathrm{~cm} \text { above the medial epicondyle at right angle to the } \\
\text { adductor muscle. }\end{array}$ & Unknown & Unknown \\
\hline
\end{tabular}

$104 \quad$ Abdominal percussion and auscultation

$C M \& R 2020: 2-3$ (August) signs, 1924-1980 
of the duodenum. Directly to the right of the linea alba and slightly below the midst of the costal arch and navel, in all cases of duodenal ulcer by our method of examination, a sharply circumscribed painful area usually the size of a two-mark fragment is found similar to that found in gastric ulcers. In the course of the appropriate treatment diminution and final disappearance of this area occurs. ${ }^{10(\text { p. } 565 ; \text { emphasis added) }}$

He further described the benefits of percussion over palpation to detect ulcers (Table 2):

From this, the most important fact is that the direct percussion of the epigastrium brings to our attention even in cases of an existing ulcer where usual palpation of the stomach completely fails. First of all, there are a number of gastric ulcers which, although palpable, are able to withstand the pressure of the palpating hand without causing a pain sensation. In such cases the much stronger stimulus that direct percussion exerts on the ulcer will still produce a pain that will allow us to recognize an existing ulcer. (...) Often, however, owing to its anatomical position, the ulcer cannot be reached by palpation at all, and consequently the symptom of pressure-pain, which is so important for the diagnosis, cannot be proven according to the methods of examination hitherto. However, the vibration produced by the direct percussion of the epigastrium propagates wave-like in all directions and, as a painful stimulus, reaches the gastric ulcer, wherever it may be located. ${ }^{10(\text { p. } 564)}$
Mendel reported that this technique can distinguish gastric and duodenal ulcers from other diseases found within the epigastrium including gastritis, perigastritis, carcinoma, cholelithaisis, colon discomfort, and epigastric hernia by the sharply defined border on percussion.

Meyer and Golden ${ }^{11}$ employed Mendel's test incorporating Libman's styloid pressure test that determines sensitivity to pain by pressing over the styloid process. The Libman's pain sensitivity test divides patients into a sensitive and hyposensitive group. Pain localized by Mendel's test in a patient with a negative Libman's test is diagnostic in patients with suspected peptic ulcer disease. In their study of 62 patients, peptic ulcers were identified with fluoroscopic imaging in 48 patients; 36 had a positive Mendel's test and 33 a hyposensitive Libman's test. In the 14 patients with no ulcer identified, 4 had a positive Mendel's and hyposensitive Libman's test. In 43 patients with presumed absence of peptic ulcer disease, Mendel's test was positive in 6 , and a hyposensitive response to Libman's test occurred in 42 patients. ${ }^{11}$ The authors concluded that in hyposensitive patients with a typical ulcer history and negative radiographic imaging, a positive Mendel's test is diagnostic. In those with an atypical history, a patient with positive Mendel's test and a hyposensitive Libman's test is valuable in assisting a diagnosis of peptic ulcer disease. ${ }^{11}$ It is of interest that Kurt Mendel (1874-1946), another German neurologist, described the dorsal reflex of the foot sign and in conjunction with Vladmir Mikhailovich Bekhterev (1857-1927), a Russian neurologist, the signs of anesthesia of the popliteal space, deep hypogastric, pupil and nasal reflex, and the cuboidodigital reflex. ${ }^{12}$

Table 2. Significance of a positive diagnostic percussion maneuver

\begin{tabular}{|c|c|}
\hline Sign & Interpretation \\
\hline \multirow{4}{*}{ Mendel-Razdolsky } & $\begin{array}{l}\text { Mendel } \\
\text { Method for detecting and determining the size of a gastric and duodenal ulcer and distinguishing } \\
\text { it from other diseases within the epigastrium. }\end{array}$ \\
\hline & $\begin{array}{l}\text { Razdolsky } \\
\text { Normal: Contraction of the contralateral tensor fascia latae and with a stronger percussion stroke, } \\
\text { also contraction of the quadricep muscle. Additionally, in } 20-25 \% \text {, there is a weaker contraction of } \\
\text { the homologous adductors. }\end{array}$ \\
\hline & $\begin{array}{l}\text { Unilateral disease to the coricospinal tract: Contraction increased on same side of diseased } \\
\text { segment. }\end{array}$ \\
\hline & $\begin{array}{l}\text { Motor nuclei or peripheral nerves disease: Homolateral and crossed spinal adductor reflex absent } \\
\text { on diseased side. }\end{array}$ \\
\hline Kenawy & Found in patients with splenic vein enlargement with portal hypertension and splenomegaly. \\
\hline Nixon & Method for determining spleen size. \\
\hline Castell & Method for determining milder degrees of splenic enlargement. \\
\hline Hannington-Kiff & Identifying a strangulated obturator hernia. \\
\hline
\end{tabular}




\section{Kenawy Sign}

We have been able to identify much historical information on Dr. Kenawy. Mohammed Radwan Kenawy served as contemporary medical tutor at the Fouad I University Hospital in Cairo, Egypt in the late 1930s and as Faculty of Medicine at the Medical Unit of Kasr El-Aini Fouad I University, Cairo in the 1950s.

Kenawy described a continuous venous hum in patients with splenic vein enlargement, portal hypertension and splenomegaly. The venous hum is heard on auscultation below the xiphoid process and is accentuated during inspiration (Table 1). The increased sound intensity during inspiration is believed to be due to splenic compression by the diaphragm associated with augmented blood flow through the engorged splenic vein (Table 2). ${ }^{13-15}$

Von Jacksch in 1899 reported a case of cirrhosis with the presence of a venous hum located on the left side of the epigastrium in the angle between the large liver and spleen. Autopsy identified the presence of a dilated splenic vein with the murmur believed to arise from this location. ${ }^{16}$ We are unaware of any study that validated this sign.

\section{Nixon Sign}

Robert K. Nixon (1921-1997) was Clinical Assistant of Medicine at Northwestern University School of Medicine and Associate Attending Physician, Department of Medicine, Cook County Hospital in $1954 .{ }^{17} \mathrm{He}$ also served as a physician in the Department of Medicine at Henry Ford Hospital in Detroit Michigan and Clinical Professor of Medicine at the University of North Carolina School of Medicine. Nixon (1954) described a method for determining spleen size (Tables 1 and 2):

The patient is placed in the right lateral recumbent position with the left arm extended forward and upward sufficiently to clear the left lower part of the thorax. In this position the spleen lies above both stomach and colon, permitting determination of its upper and lower borders of dullness. After palpation for the lower border of inspiration, percussion is initiated at the lower level of pulmonary resonance in approximately the posterior axillary line and carried downward obliquely on a general perpendicular line toward the lower midanterior costal margin. Normally the upper border of dullness is measured 6 to $8 \mathrm{~cm}$ above the costal margin. Dullness increased over $8 \mathrm{~cm}$ is indicative of splenic enlargement in the adult. ${ }^{17(\text { p. } 166 ; \text { emphasis added) }}$

This position, according to Nixon, is particularly useful in patients with minimal splenic enlargement with muscular and rigid abdominal wall, as well as in patients unable to cooperate by taking a deep breath during palpation. Nixon stated the validity of this method "by successful splenic aspiration biopsies in 60 cases." (...) "A considerable number were performed on spleens in which the lower edge was barely palpable, requiring accurate appraisal of the upper border for the intracostal approach." ${ }^{17(\text { p. 166) }}$

Different methods of percussion of the spleen have been employed using both direct (single) and mediate (two-bodies) techniques. Regardless of the method, authors typically place the patient in the supine position. Charles Hoover recommended using a direct technique in which

The patient should lie on his back so as to bring the spleen in intimate contact with the ribs. The lower border of the lung in the posterior axillary line is first determined and then percussed in gently in the intercostal space toward the median line at right angles to the costal border. ${ }^{18(\text {. . })}$

Sullivan compared percussion by Nixon's method, Castell's method, and splenic palpation in the supine and left lateral position to scintigraphy. A sensitivity and specificity using the Nixon method of 59\% and 94\%, respectively, was found. ${ }^{19}$ McGee reported a sensitivity ranging from 25\%-66\%, specificity $68 \%-95 \%$, positive likelihood ratio of 2.0 , and negative likelihood ratio of $0.7 .{ }^{20} \mathrm{~A}$ review by Barkum and Grover $^{21}$ reported a LR+ of 3.6 (1.8-7.3), LR- 0.41 (0.26$0.64)$ and a diagnostic odds ratio of 8.9 (3.1-1.25), suggesting that percussion by this method may be useful for detecting splenomegaly.

In general, there is poor intra-observer agreement using percussion alone to measure the size of the spleen. Interestingly, incorporating pre-test clinical suspicion of splenomegaly improves the performance of these tests and provides a rational for ordering additional ultrasonographic imaging. Thus, if the pre-test probability is $<10 \%$, neither percussion or palpation is sufficiently sensitive to rule out splenomegaly, and the specificity is not sufficiently high to rule in splenomegaly. If the clinical suspicion is higher $(>10 \%)$, percussion and palpation can be used to rule in splenomegaly. If either percussion or palpation is present, but the other is negative, then ultrasonography is required because of the lower specificity to rule in splenomegaly. Conversely, to exclude splenomegaly, an ultrasound is required due to low sensitivity of percussion or palpation. ${ }^{22}$

\section{Castell Sign}

Donald Overton Castell (1935) received his medical degree from George Washington University School of Medicine in 1960. From 1959 to 1979 he served in the United States Navy, eventually earning the rank of captain, and from 1975 to 1979 he served as Chairman of Medicine at the National Naval Medical Center, Bethesda, Maryland. ${ }^{23}$ At the Philadelphia Naval Hospital, Castell established a clinical research center and served initially as Director of the Clinical Investigation of the US Navy Medical Corps as well as Chief of the Gastrointestinal Division and Director of Gastro-intestinal Research. 
He served as Chairman of Medicine at the National Naval Medical Center, Director of the Digestive Disease Division at Uniformed Services University (USU) (1979), Chief of Gastroenterology at Bowman Gray, Director of the Division of Gastroenterology and Hepatology at Thomas Jefferson University Hospital, and Chairman of Medicine at Graduate Hospital,which became part of the Allegheny University of the Health Services (1992). ${ }^{24}$ In 1998 he served as the 92nd President of the American Gastroenterological Association. ${ }^{24}$ Since 2001, he has been Professor of Medicine and Director of the Esophageal Disorders Program at the Medical University of South Carolina, Charleston, having established an education and teaching program in esophageal disorders.

His interest in gastroenterology spans multiple therapeutic areas including ammonia in patients with cirrhosis, the effects of gastrin on cigarette smoking, food on lower esophageal sphincter tone, calcium channel blocker on esophageal function, unexplained chest pain, motility disorders, endoscopic ultrasonography liver transplantation, and inflammatory bowel disease. ${ }^{24} \mathrm{He}$ received numerous awards in areas of teaching, research, and leadership including in 1992 from the American Gastroenterology Association, the Kirsner Award for Clinical Research, and in 1995 Bakers Presidential Leadership Award from the American College of Gastroenterology. ${ }^{24}$

In 1967 he described the "The Spleen Percussion Test" as a useful diagnostic technique for determining milder degrees of splenic enlargement (Table 2). The technique is performed using the middle finger of the left hand as a pleximeter (Table 1):

With the patient in the supine position percussion in the lowest intercostal space (eighth or ninth) in the left anterior axillary line usually produces a resonant note if the spleen is normal in size. Furthermore, the resonance persists with full inspiration. As the spleen enlarges, the lower pole of this organ is displaced inferiorly and medially. This may produce a change in the percussion note in the lowest left interspace in the anterior axillary line from resonance to dullness with inspiration. ${ }^{25(\mathrm{p} .1265 ;}$ emphasis added)

Thus, a positive Castell's sign refers to the presence to a change in the percussion note from resonance to dullness during full inspiration compared with full expiration in the lowest left intercostal space on the anterior axillary line. ${ }^{25} \mathrm{He}$ confirmed the usefulness of this maneuver using a radioisotope scan in 10 patients with a nonpalpable spleen and a positive percussion sign compared to 10 controls with no splenic disease.

The "percussion sign" may be negative in patients with marked splenomegaly or fluid in the stomach or stool in the adjacent colon. A sensitivity of $76 \%$ and specificity of $46 \%$ has been reported for this test. ${ }^{26} \mathrm{McGee}$, in a comprehensive evaluation of prior studies, found that the sensitivity ranged from $25 \%-85 \%$, specificity $32 \%-94 \%$, positive likelihood ratio of 1.7 , and negative likelihood ratio of 0.7 . Using spleen scintigraphy as a criterion standard, detection of splenomegaly using Castell's method was found to have a sensitivity and specificity of $82 \%$ and $83 \%$, respectively. ${ }^{20}$ Thus, percussion using Castell's method is limited in its ability to detect splenomegaly.

\section{Hannington-Kiff Sign}

We were only able to identify limited historical information about John G. Hannington-Kiff. His primary areas of research and medical practice were in pain management and anesthesia. In 1974, he developed a technique for stellate ganglion block and regional intravenous sympathetic block with guanethidine. ${ }^{27,28}$ During the 1980 s he served as Consultant Anesthetist and Director of the Pain Relief Centre, Frimley Park Hospital, Surrey, England. In 1981, he was awarded the Jacksonian Prize from the Royal College of Surgeons of England for his dissertation entitled The relief of dystrophic inflammatory and spastic conditions of limbs by the local deposition of high doses of drugs administered during regional circulatory occlusion with a tourniquet. ${ }^{29}$ This award is considered the premier award for Fellows and Members of the Royal College of Surgeons who "aspire to high places in surgery, dentistry and anesthetics." He was the first anesthetist to have received this honorific award. ${ }^{29}$

He described the use of the thigh abductor stretch reflex as a means for identifying a strangulated obturator hernia. The adductor reflex is elicited by:

(...) a firm blow from a patellar hammer over thumb or index finger laid at right angles across the adductor muscles about $5 \mathrm{~cm}$ above the medial epicondyle of the femur. In this way any contraction of the adductor muscle can be felt as well as seen, and the patient will be saved some discomfort from the blow of the hammer. ${ }^{30(\mathrm{p} .180 \text {; emphasis added) }}$

The pathogenesis is caused by pressure on the obturator nerve by an obturator hernia. This sign, unlike the HowshipRomberg test, is an objective means for diagnosing strangulated obturator hernia. Hannington-Kiff sign is believed to be more sensitive and as specific as the HowshipRomberg sign. ${ }^{30}$ We are unaware of any studies that have directly evaluated the sensitivity or specificity of this sign.

\section{Conclusion}

During this period clinicians, including Nixon and Castell, continued to be reliant upon perfecting their physical examination skills of percussion to determine spleen size, while Mendel developed a method for identifying peptic ulcer disease. These maneuvers became forgotten and abandoned by physicians with the emergence of ultrasonography, computed tomography, and endoscopic techniques. Nonetheless, these signs remain valuable in physical diagnosis 
and may still assist clinicians in differentiating different condition and selecting appropriate and cost-effective approaches to patient care.

\section{References}

1. Skinner A. The Origin of Medical Terms. Baltimore: Williams \& Wilkins Co.; 1949.

2. Laennec RTH. Immediate Auscultation. In: Treatise of the Diseases of the Chest and on Mediate Auscultation. London: Thomas \& George Underwood; 1829. 24-27. [Translated from the latest French Edition with notes and sketches of the authors life by John Forbes.]

3. Laennec RTH. De l'Auscultation Médiate ou Traité du Diagnostic des Maladies. Fondé Principalement sur ce Nouveau Moyen D'Exploration. Tome Premier. Paris: J.A. Brosson et J.S. Chaudé Libraires; 1819: 6-7.

4. Bojanic Z. Ivan Yakovlievich Razdolskii. In: Whonamedite? A dictionary of medical eponyms. Available at: http://www. whonamedit.com/. Accessed January 29, 2018.

5. Lekar PG. Razdolsky Ivan Yakovlevich. A dictionary of medical eponyms. Available at: http://www.whonamedit.com/doctor. cfm/2387.html. Accessed December 12, 2017.

6. Krayem BA. Appendicitis Baher. SCRIBD. Available at: https:// www.scribd.com/document/75678908/Appendicitis-Baher. Accessed December 8, 2017.

7. Zaporozhchenko BS. Faculty Surgery. A course of lectures. The Odessa State Medical University. Medical Student's Library. Odessa. The Odessa State Medical University 2009. Available at: https://onmedu.edu.ua/information-foreign-citizens/internationalfaculty/?lang=en. Accessed December 8, 2017.

8. Appendicitis in adults. 2015 medicine-worlds. Available at: http:// en.medicine-worlds.com/appendicit-u-vzroslyh.htm. Accessed December 10, 2017.

9. Rasdolsky I. Der gekreuzte spino-adductorische Reflex. Pflugers Arch Gesamte Physiol Menschen Tiere. 1924;202(1):658-663.

10. Mendel F. Die direkte Perkussion des Epigastrium, ein diagnostisches Hilfsmittel bei Ulcus ventriculi. Munch Med Wochenschr. 1903;50:564-565.

11. Meyer J, Golden JS. Epigastric percussion in peptic ulcer. Am J Dig Dis. 1936;3(1):6-7.

12. White FA. Physical Signs in Medicine and Surgery: An Atlas of Rare, Lost and Forgotten Physical Signs. London: British Museum Press Books; 2009.

13. Prabhu S. Clinical Signs and Syndromes in Surgery. New Delhi: Jaypee Brothers Medical Publishers; 2011.

14. Kenawy M. Continuous venous hum in bihlarzial cirrhosis of the liver. Lancet. 1937;229(5935):1281-1285.

15. Kenawy MR. Venous hum in bilharzial cirrhosis of the liver. Lancet. 1939;233(6032):821-822.

16. von Jacksch. Kasuistische Beiträge zur Kenntniss der im Verlaufe der chronischen interstitiellen Leberentzündung vonkommenden Gefässgeräusche. Präger med. Woch; 1899;24:535,560,585.

17. Nixon RK Jr. The detection of splenomegaly by percussion. N Engl J Med. 1954;250(4):166167.

18. Hoover CF. The diagnosis of typhoid fever. Cleveland Journal of Medicine. 1901;6(1):5-8.

19. Sullivan S, Williams R. Reliability of clinical techniques for detecting splenic enlargement. BMJ 1976;2(6043):1043-1044.

20. McGee SR. Evidence-based physical diagnosis. 3rd ed. Philadelphia: Elsevier; 2012. 428440.

21. Barkum AN, Grover SA. Splenomegaly. In: Simel DL, Rennie D, eds. JAMA Evidence. The rational clinical examination. Evidence based clinical diagnosis. New York: McGraw Hill
Medical; 2009. 611-613.

22. Grover SA, Barkun AN, Sackett DL. The rational clinical examination. Does this patient have splenomegaly? JAMA. 1993;270(18):2218-2221.

23. Castell DO, Sataloff RT, Katz PO, Sataloff DM. Reflux Laryngitis and Relate Disorders. 3rd ed. San Diego: Plural Publishing Inc; 2005.

24. Frank BB; American Gastroenterological Association. Our new president-Donald O. Castell, M.D. Gastroenterology. 1998;114(5):1091-1094.

25. Castell DO. The spleen percussion sign. A useful diagnostic technique. Ann Intern Med. 1967;67(6):1265-1267.

26. Barkun AN, Camus M, Green L, et al. The bedside assessment of splenic enlargement. Am J Med. 1991;91(5):512-518.

27. Hannington-Kiff JG. Intravenous regional sympathetic block with guanethidine. Lancet. 1974;303(7865):1019-1020.

28. Hannington-Kiff JG. Relief of causalgia in limbs Yb regional intravenous guanethidine. BMJ. 1979;2(6186):367-368.

29. News and Notices, Award of the Jacksonian Prize of the Royal College of Surgeons of England. Anaesthesia. 1981;36:731-746.

30. Hannington-Kiff JG. Absent thigh adductor reflex in obturator hernia. Lancet. 1980;1(8161):180.

\section{Author Affiliations}

Vaibhav Rastogi, $M D^{*}$; Devina Singh, MD ; Halil Tekiner, PhDf; Fan Ye, MD*; Joseph J Mazza, MD\$; and Steven H. Yale, MD\|

*University of Central Florida College of Medicine, Graduate Medical Education, 6850 Lake Nona Blvd, Orlando, Florida, USA

†University of Florida, Department of Medicine, 2000 SW Archer Rd, Gainesville, Florida, USA

$\$$ Erciyes University School of Pharmacy, Department of the History of Pharmacy and Ethics, Talas, Kayseri 38280 Turkey

\$Marshfield Clinic Research Institute, 1000 North Oak Avenue, Marshfield, Wisconsin, USA

UUniversity of Central Florida College of Medicine, Department of Internal Medicine, Orlando, Florida, USA 